\title{
Primary triage nurses do not divert patients away from the emergency department at times of high in-hospital bed occupancy - a retrospective cohort study
}

\author{
Mathias C Blom ${ }^{1 *}$, Karin Erwander ${ }^{1}$, Lars Gustafsson ${ }^{2}$, Mona Landin-Olsson ${ }^{1}$, Fredrik Jonsson ${ }^{3}$ and Kjell Ivarsson ${ }^{1}$
}

\begin{abstract}
Background: Emergency department (ED) overcrowding is frequently described in terms of input- throughput and output. In order to reduce ED input, a concept called primary triage has been introduced in several Swedish EDs. In short, primary triage means that a nurse separately evaluates patients who present in the Emergency Department (ED) and either refers them to primary care or discharges them home, if their complaints are perceived as being of low acuity. The aim of the present study is to elucidate whether high levels of in-hospital bed occupancy are associated with decreased permeability in primary triage. The appropriateness of discharges from primary triage is assessed by $72-h$ revisits to the ED.
\end{abstract}

Methods: The study is a retrospective cohort study on administrative data from the ED at a 420-bed hospital in southern Sweden from 2011-2012. In addition to crude comparisons of proportions experiencing each outcome across strata of in-hospital bed occupancy, multivariate models are constructed in order to adjust for age, sex and other factors.

Results: A total of 37,129 visits to primary triage were included in the study. $53.4 \%$ of these were admitted to the ED. Among the cases referred to another level of care, $8.8 \%$ made an unplanned revisit to the ED within $72 \mathrm{~h}$. The permeability of primary triage was not decreased at higher levels of in-hospital bed occupancy. Rather, the permeability was slightly higher at occupancy of 100-105\% compared to <95 \% (OR $1.0995 \%$ Cl 1.02-1.16). No significant association between in-hospital bed occupancy and the probability of 72-h revisits was observed.

Conclusions: The absence of a decreased permeability of primary triage at times of high in-hospital bed occupancy is reassuring, as the opposite would have implied that patients might be denied entry not only to the hospital, but also to the ED, when in-hospital beds are scarce.

Keywords: Emergency medicine, Bed occupancy, Emergency Department revisits, Triage

\section{Background}

Emergency Department (ED) overcrowding has received considerable attention in the literature [1-3]. ED overcrowding is defined as a situation where the need for emergency services exceeds available resources, and its causes have been divided into input, throughput and output factors [4], of which the last have been suggested to be

\footnotetext{
* Correspondence: mathias.blom@med.lu.se

${ }^{1} \mathrm{KKVL} /$ Avd för medicin, Universitetssjukhuset, Hs 32, EA-blocket, plan 2, 221

85 Lund, Sweden

Full list of author information is available at the end of the article
}

the most influential $[1,5]$. Our group recently showed that scarcity of in-hospital beds (i.e., hospital crowding) not only increases ED length of stay (EDLOS) [6], but also causes more patients to be discharged from the ED rather than being admitted to the hospital [7, 8].

Several strategies aimed at reducing ED overcrowding through managing ED input- and throughput factors have been proposed [9]. These include fast-track service lines [9, $10]$, adding a physician to triage [10-13], test ordering by nurses $[9,10,14,15]$ and introducing primary care professionals in hospital EDs [16]. Other strategies aim at 
improving discharge planning and follow-up for patients with chronic diseases [17-19], and still others have been directed at diverting patients away from the ED [20]. In order to decrease the inflow of non-urgent patients into the ED, such a strategy has been implemented in the county council of Region Skåne in southern Sweden. The concept is called "primary triage" and its essence is that a nurse evaluates patients who are considered non-urgent upon registration in the ED. After the assessment, the nurse could admit patients to the ED, refer them to primary care or discharge them home (often with medical advice).

\section{Methods}

Aim

The aim of the present study is to evaluate whether the permeability of primary triage decreases at times of high in-hospital bed occupancy (i.e., whether patients are increasingly denied entry into the ED, by primary triage). An association between in-hospital bed occupancy and decreased permeability in primary triage would be worrisome, as that could suggest that nurses in primary triage deny patients evaluation by an ED physician when knowing that hospital beds are scarce. A secondary aim is to evaluate the appropriateness of discharges from primary triage by investigating whether the proportion of patients making an unplanned 72-h revisit to the ED is associated with the level of in-hospital bed occupancy.

\section{Study design}

The study was conducted as a retrospective cohort study on administrative data from the ED at a 420-bed hospital in southern Sweden.

\section{Inclusion criteria}

All patients registered in the ED information system Patientliggaren in 2011-2012 and who were assessed in primary triage were included in the study.

\section{Sample size calculation}

In order to limit bias, the study material was not subject to further restrictions. Post-hoc power calculations were performed to determine the number of strata (see cut-offs in the "variables" section) of inhospital bed occupancy to use for group comparisons $(\alpha=0.05,1-\beta=0.80)$ [21]. Absolute differences of $5 \%$ in the proportion of patients admitted to the ED and $2 \%$ in the proportion of patients revisiting were considered clinically meaningful for study purposes. The magnitude of the differences was arrived at by a consensus decision in the study collaboration. Sample sizes allowing for 10 events per predictor were considered appropriate for multivariate analysis [22].

\section{Setting}

Helsingborg general Hospital is one of four hospitals providing 24/7 emergency care in Region Skåne in southern Sweden. Its ED serves a population of around 250,000, which expands to more than 300,000 in the summer due to tourism. It is an academic teaching hospital, providing education for medical students and Emergency Medicine residents. The annual ED census is around 60,000, with approximately $15 \%$ of patients arriving by ambulance.

Upon arrival to the ED, patients are registered in the information system Patientliggaren ${ }^{\circ}$. Until $1^{\text {st }}$ January 2012, registration was performed by a nurse in the "spot-check" facility. The nurse did not measure vital parameters or conduct any physical examination, beyond recording the main complaint and a short anamnesis. The spot-check nurse could refer patients either directly to the ED, or (if their complaint was considered benign) to primary care without further assessment in the ED. If unsure whether the patient should be assessed in primary care or in the ED, the nurse could refer patients to primary triage, situated in the same physical facilities as the ED. Primary triage was staffed by a nurse who was able to conduct physical examinations and order laboratory tests. Beginning January 1, 2012, the task of registration was delegated to a secretary and the spot-check facility ceased to be. The secretary could not refer patients to primary care, but was limited to admitting patients directly to the ED or referring them to primary triage. Strict guidelines were developed for the secretary to follow (Table 1). After evaluating patients, the nurse in primary triage could admit them to the ED, refer them to primary care or discharge them home. To aid her decision, the decision-support "Triagehandboken" [23] was available in print and electronically. Nurses in primary triage could consult one of the ED physicians when in doubt, but no physician was on permanent duty in primary triage. Primary triage nurses could be asked to assist staff inside the ED during the entire studyperiod. Primary triage could also be bypassed at times it was experiencing long queues. Patients who were referred to the ED by a physician were directly admitted to the ED after registration and hence bypassed primary triage. Patients arriving by ambulance were admitted to the ED directly (see Additional file 1 for a schematic picture of the ED front-end organization). Patients who were referred to primary care from spot-check or from primary triage were guaranteed a medical evaluation by a nurse in primary care the same day or the day after (depending on hours of primary care availability, generally until $5 \mathrm{pm}$ ). One primary-care facility would accept patients outside office hours (until $8 \mathrm{pm}$ ), but was located $15 \mathrm{~min}$ away by car. Hence patients often resented primary triage nurses' advice to contact this facility.

After being admitted to the ED, patients underwent secondary triage (an algorithm for prioritizing patients 
Table 1 Criteria applied to direct patients to primary triage (used by secretary)

All the criteria below need to be fulfilled before a patient can be
referred to primary triage
Age $>1$ and $<70$
Fully awake, without dyspnoea, pallor or sweatiness
Self-ambulating without problems
5 or fewer patients waiting for primary triage
Each of the following groups of patients is directly admitted to the ED
after registration
Dyspnoea
Chest pain
Abdominal pain
Patients with known cancer
Foreign body
Known atrial fibrillation (where the patient suspects relapse)
Chronic bowel disease
Problems related to nasogastric tubes, catheters and plasters
Scrotal pain
Urinary obstruction or haematuria
Revisits (planned and unplanned)

depending on vital parameters and main complaints, similar to what is used in most EDs worldwide). During the study period, the 4-level triage system "medical emergency triage and treatment system" (METTS) was used in secondary triage $[24,25]$. From secondary triage, patients were directed to separate units for Surgery, Orthopaedics, Medicine, Otolaryngology, gynaecology, paediatrics, ophthalmology and psychiatry in a triage-to-specialty model. A complementary unit staffed by emergency physicians capable of handling various complaints, except for psychiatric, otolaryngologic, ophthalmologic and paediatric (medicine) complaints, was introduced in 2010 and operates from 8 am to 11 pm daily.

\section{Data sources}

Data on in-hospital bed occupancy was retrieved from an occupancy database used by hospital management for quality assurance activities. Occupancy was measured as the number of occupied beds divided by the number of available beds (i.e., staffed beds) in the hospital. The data source is the hospital administrative system used for billing (PASiS). The database is updated at the beginning of every hour by an application developed by the hospital informatics unit (QlikView software). Data on ED visits was retrieved from the ED information system Patientliggaren* Data gathering and linking was performed by the hospital informatics unit using QlikView ${ }^{\circ}$ software. No system crashes were reported during the study period.

\section{Statistics}

Post hoc power calculations revealed that the study sample was large enough to detect the pre-specified differences for strata of in-hospital bed occupancy of $<95 \%, 95-100 \%$, $100-105 \%$ and $>105 \%$ for ED admissions and $<95 \%$, 95$100 \%$ and $>100 \%$ for 72 -h revisits. Strata were proposed prior to analysis. Since $95 \%$ reflects the median occupancy at the hospital, $<95 \%$ was used as a commonsense reference [26]. Proportions of patients experiencing each outcome were compared across strata using Fisher's exact test.

Binary logistic regression models were constructed in order to adjust for the effects of other factors (please see below) that may influence the outcome (admission from primary triage to the ED). Also, a sensitivity analysis was performed, using occupancy as measured $3 \mathrm{~h}$ prior to patient presentation (rather than at presentation) in the ED. This time interval was proposed prior to analysis and reflects the median EDLOS at the study site. Variables included in the models were: sex, age group (0-1 year, 1-18 years, $18-40$ years, $40-70$ years and $\geq 70$ years), shift (0 am-8 am, 8 am- 4 pm, 4 pm-0 am), time of week (Mon, Tue-Fri, Sat-Sun), registration by a nurse (rather than a secretary) upon arrival, presentation on a shift with many visits (high inflow) to primary triage and presentation on a shift with high inflow to the ED. The decision on age intervals was based on the fact that patients $<1$ year and $\geq 70$ years were referred directly into the ED without passing primary triage, according to the guidelines to be followed by the secretary who replaced the "spot-check" nurse in January 2012. The time intervals used for shift reflect staffing patterns at the study site. The intervals used for time of week reflect the lower staffing during weekends and the higher patient flow on Mondays. The same occupancy levels as in the crude analysis were used in the multivariate models. Presentation on a shift with high inflow was constructed as a dichotomous variable, indicating presentation on one of the $25 \%$ of shifts subject to most visits (adjusted for shift type). In-hospital bed-occupancy and age were considered for inclusion in the models as continuous variables, but both violated the assumption of linearity in the logit and were therefore included as the ordinal variables described above [27]. Multicollinearity testing was performed using tolerance and VIF statistics. Independent variables were manually added to the models, rather than stepwise, in order not to exclude clinically relevant variables [28]. Model fit was evaluated through Nagelkerke's $R^{2}$. The association between each predictor and the outcome was addressed by the -2LL and the Wald statistics. Models were screened for influential cases by addressing standardized residuals. The relatively large number of comparisons warranted application of the Bonferroni correction, yielding a level of significance of $p=$ 0.006. Statistical analyses were performed in $\mathrm{IBM}^{\circ} \mathrm{SPSS}^{\circ}$ Statistics 22. Data was anonymized before analysis. 
Table 2 Descriptive statistics across outcomes

\begin{tabular}{|c|c|c|c|c|c|}
\hline \multirow[t]{2}{*}{ Variable } & & \multicolumn{2}{|l|}{ ED admission } & \multicolumn{2}{|l|}{72 h revisits } \\
\hline & & No & Yes & No & Yes \\
\hline \multirow[t]{2}{*}{ Sex } & Female & 8232 (45.8 \%) & 9745 (54.2 \%) & 7541 (91.6 \%) & 691 (8.4 \%) \\
\hline & Male & 9068 (47.3 \%) & 10084 (52.7 \%) & 8230 (90.8 \%) & 838 (9.2 \%) \\
\hline \multirow[t]{5}{*}{ Age [Years] } & $0-1$ & $82(46.3 \%)$ & 95 (53.7 \%) & 79 (96 \%) & $3(4 \%)$ \\
\hline & $1-18$ & 3028 (46.1\%) & 3545 (53.9 \%) & 2797 (92.4 \%) & 231 (7.6 \%) \\
\hline & $18-40$ & 8278 (52.5 \%) & 7478 (47.5 \%) & 7590 (91.7 \%) & $688(8.3 \%)$ \\
\hline & $40-70$ & $5071(42.1 \%)$ & 6972 (57.9 \%) & 4559 (89.9 \%) & 512 (10.1\%) \\
\hline & $>70$ & $841(32.6 \%)$ & 1739 (67.4 \%) & $746(88.7 \%)$ & 95 (11.3 \%) \\
\hline \multirow[t]{2}{*}{ Year } & 2011 & 8942 (44.8 \%) & 11032 (55.2 \%) & 8098 (90.6 \%) & 844 (9.4 \%) \\
\hline & 2012 & 8358 (48.7 \%) & 8797 (51.3 \%) & 7673 (91.8 \%) & 685 (8.2 \%) \\
\hline \multirow[t]{2}{*}{ Inflow $>75$ th percentile } & High inflow p-triage & 5786 (45.1%) & 7037 (54.9 \%) & 5234 (90.5 \%) & 552 (9.5 \%) \\
\hline & High inflow ED & 3935 (44.4%) & 4935 (55.6 \%) & 3598 (91.4 \%) & 337 (8.6 \%) \\
\hline \multirow[t]{3}{*}{ Shift } & 8 am-4 pm & 6216 (45.3 \%) & 7500 (54.7 \%) & 5753 (92.6 \%) & 463 (7.4 \%) \\
\hline & 4 pm-0 am & 8502 (49.0 \%) & 8859 (51.0 \%) & 7784 (91.6 \%) & 718 (8.4%) \\
\hline & 0 am-8 am & 2582 (42.7 \%) & 3470 (57.3 \%) & 2234 (86.5 \%) & 348 (13.5\%) \\
\hline \multirow[t]{3}{*}{ Time of week } & Mon & 2538 (47.5 \%) & 2810 (52.5 \%) & 2325 (91.6 \%) & $213(8.4 \%)$ \\
\hline & Tue-Fri & 8510 (46.0 \%) & 9972 (54.0 \%) & 7789 (91.5 \%) & $721(8.5 \%)$ \\
\hline & Weekend & $6252(47.0 \%)$ & 7047 (53.0 \%) & 5657 (90.5 \%) & 595 (9.5 \%) \\
\hline Total & & 17300 (46.6 \%) & 19829 (53.4 \%) & 15771 (91.2 \%) & 1529 (8.8\%) \\
\hline
\end{tabular}

\section{Results}

160,462 visits were registered in Patientliggaren ${ }^{\circ} 2011-$ 2012. 37,129 visits were evaluated in primary triage and 19,829 (53.4 \%) of these were admitted to the ED. Of the 17,300 cases discharged from primary triage, 1,529 (8.8 \%) made an unplanned revisit to the ED within $72 \mathrm{~h}$.

\section{Crude analysis}

The proportion of visits to primary triage resulting in admission to the ED was $52.3 \%$ at in-hospital bedoccupancy $<95 \%, 53.5 \%$ at $95-100 \%, 56.0 \%$ at $100-$ $105 \%$ and $57.3 \%$ at occupancy $>105 \%(p<0.001)$. Post hoc power analysis indicated that the study did not have sufficient power to establish the difference between occupancy $95-100 \%$ and the reference category. Using the occupancy as measured $3 \mathrm{~h}$ prior to patient presentation yielded the following proportions: $52.6 \%$ admitted to the ED at occupancy $<95 \%, 53.7 \%$ at $95-100 \%, 54.8 \%$ at $100-105 \%$ and $55.9 \%$ at $>105 \%(p=0.003)$. Post hoc power analysis indicated that the study did not have sufficient power to establish the difference between either occupancy $95-100 \%$ or $>105 \%$ and the reference category.

Among the 17,300 cases who were discharged from primary triage, the proportion of unplanned revisits to the ED within $72 \mathrm{~h}$ was $8.8 \%$ at occupancy $<95 \%, 9.0 \%$

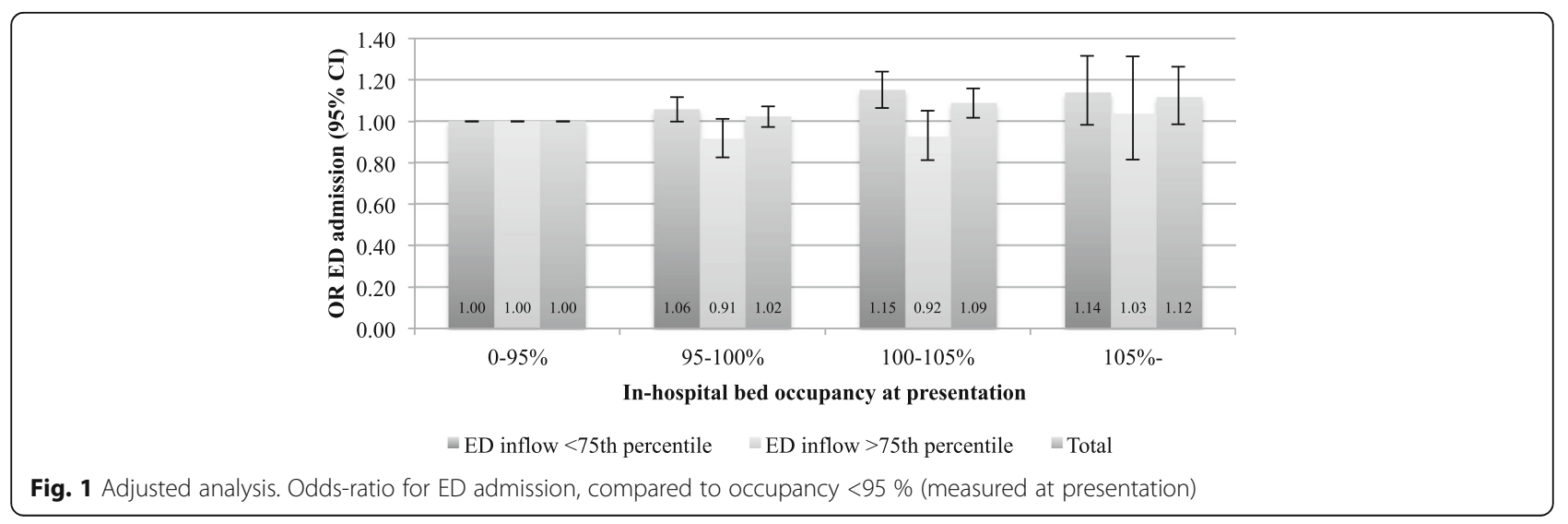




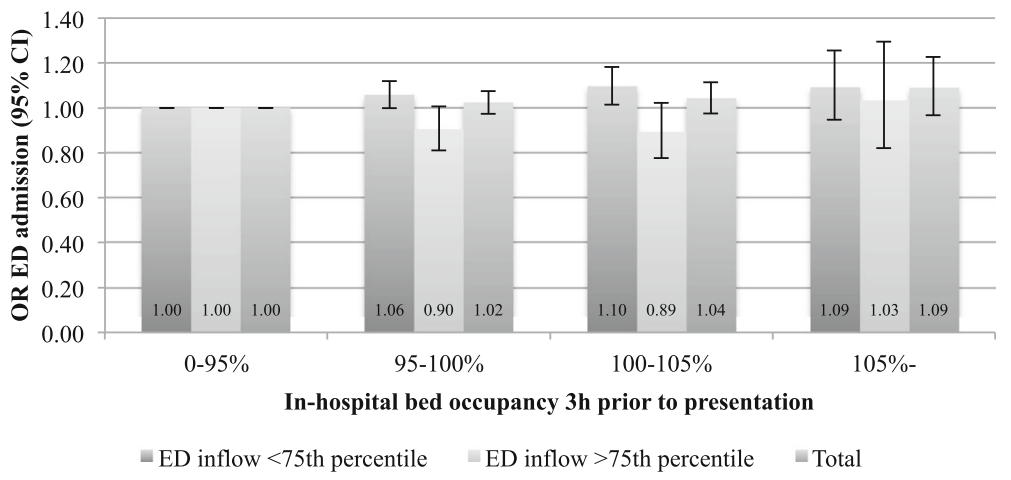

Fig. 2 Adjusted analysis. Odds-ratio for ED admission, compared to occupancy <95 \% (3 h timelag)

at $95-100 \%$ and $8.7 \%$ at $>100 \%(p=0.885)$. Using the occupancy as measured $3 \mathrm{~h}$ prior to patient presentation yielded proportions of $9.4 \%$ at occupancy $<95 \%, 8.2 \%$ at $95-100 \%$ and $8.2 \%$ at $>100 \%(p=0.020)$. Post hoc power calculations indicated that the study did not have sufficient power to establish these differences. Basic descriptive statistics across each of the outcomes are shown in Table 2.

\section{Adjusted analysis}

All independent variables screened for inclusion in the multivariate models were included in the preliminary primary effects models. The interaction term of inhospital bed occupancy*high ED inflow was significantly associated with the outcome in both models addressing the proportion admitted to the ED. This warranted stratification by high ED inflow, in addition to the analysis with the interaction term omitted.

Neither of the analyses indicated problems with multicollinearity or multivariate outliers. The odds-ratio (OR) for ED admission for different levels of the exposure variable is shown in Figs. 1 and 2. The only significant difference in ED admission was found at occupancy 100$105 \%$ compared to <95 \% (OR $1.0995 \%$ CI 1.02-1.16). This effect did not remain in the sensitivity analysis. After stratifying for high ED inflow, the effect was visible in both the main analysis and the sensitivity analysis for shifts not experiencing high ED inflow, with 95 \% CI for OR 1.061.24 and 1.01-1.18 respectively. The $p$-values from the Wald test were not statistically significant after applying the Bonferroni correction.

Neither model addressing ED admission displayed any large standardised residuals. No significant differences in $72-\mathrm{h}$ revisits were revealed in any of the models (see Figs. 3 and 4). The models addressing 72-h revisits displayed some disturbing residual statistics, which is why they are considered less reliable than those addressing ED admission. A detailed account of the multivariate models is given in Additional files 2 and 3.

\section{Discussion}

Study results do not suggest that the permeability of primary triage decreases at higher levels of in-hospital bed

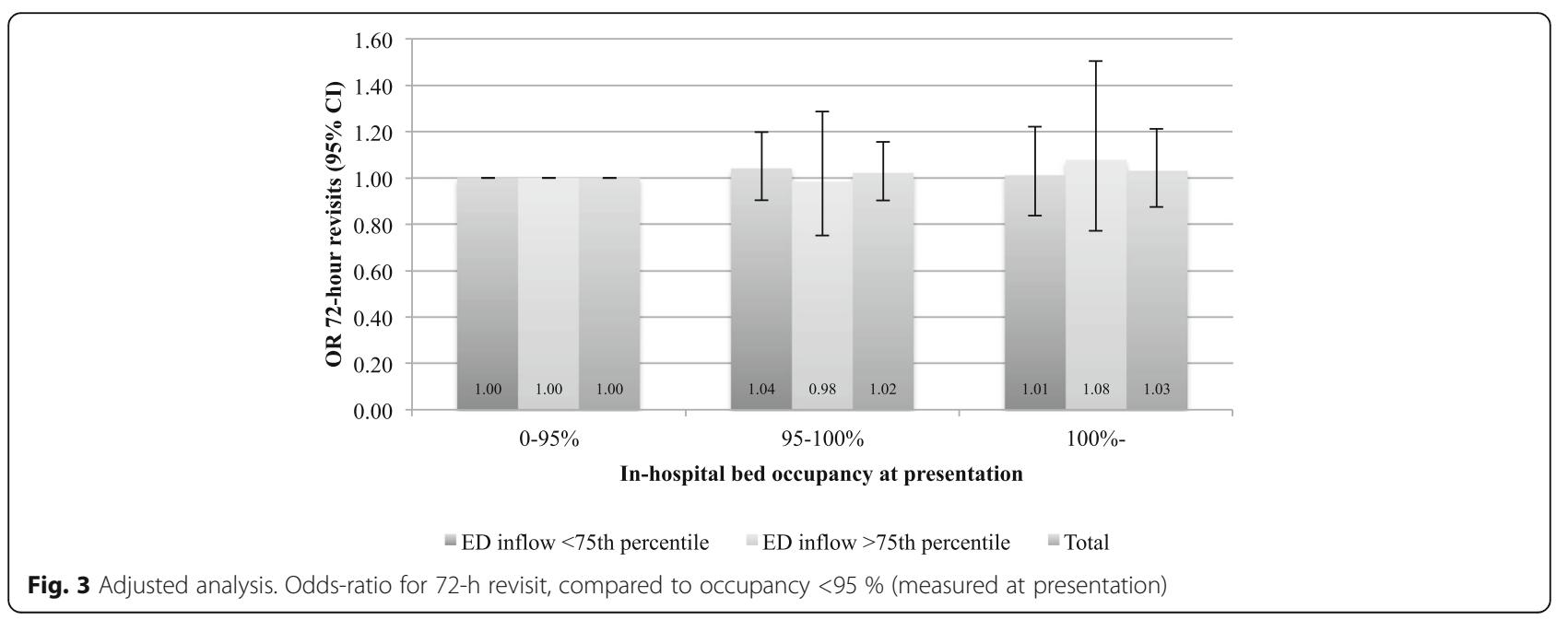




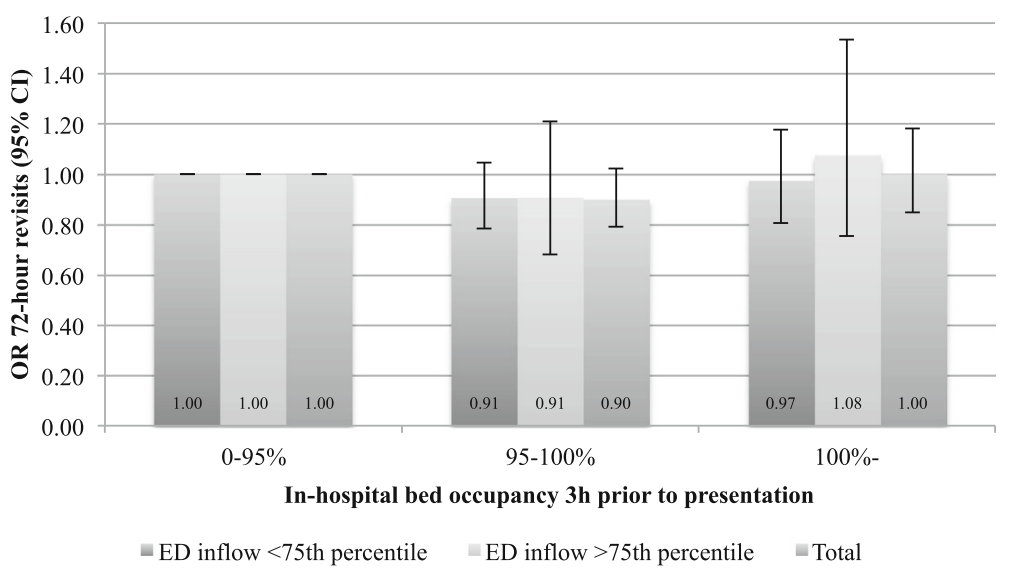

Fig. 4 Adjusted analysis. Odds-ratio for 72-h revisit, compared to occupancy $<95 \%$ (3 h timelag)

occupancy. This holds true for occupancy measured at patient presentation as well as $3 \mathrm{~h}$ prior. The differences revealed in the crude analysis rather pointed towards an increased permeability of primary triage at occupancy $>105 \%$ and at $100-105 \%$ compared to at $<95 \%$. Even though these differences were smaller than what was considered clinically meaningful prior to conducting the study, the post hoc power analysis revealed adequate statistical power and the findings deserve some elaboration. It is possible that the results reflect a situation occurring when nurses in primary triage are asked to assist ED staff at times of high workload. The proposed causal chain is then that, when their workload is high, nurses in primary triage display a tendency to admit patients to the ED when in doubt, rather than to invest additional time in undertaking a more thorough evaluation. This would imply that the intended effect of primary triage diminishes when it is needed the most (i.e., when strain on ED staff is high). The effect of bypassing primary triage altogether could not be measured in the present study, since only patients assessed in primary triage were included.

Limitations in study power led to the collapsing of occupancy-strata for the analysis of 72-h revisits, which should be able to detect differences in the proportions revisiting the ED of $2 \%$ and larger. The lack of a significant association between in-hospital bed occupancy and the proportion of 72-h revisits suggests that the appropriateness of discharges from primary triage was not severely affected by in-hospital bed occupancy. This would be in line with the main findings, which suggest that patients are not "bounced" by primary triage to a larger extent when in-hospital bed occupancy is high.

Since registration in Patientliggaren is mandatory for all patients entering the facility, differential losses of data are unlikely. This is supported by the absence of system crashes during the study period. However, the generalizability of the results is impaired because of the fact that the study was conducted at a single ED. This is especially true if comparing to systems where legislation (e.g., U.S. EMTALA) prohibits diversion from the ED without proper medical screening. Even though strategies to reduce ED input by diverting patients to other levels of care are becoming less popular internationally [29], they are not uncommon in Sweden. Even though some patients presenting in the ED may do so inappropriately, the authors believe that using primary triage nurses to divert patients away from the ED may be risky, since a thorough evaluation is often required to rule out serious underlying disease. More thoroughly researched strategies to deal with less urgent patients in the ED include introducing primary care professionals [16] and fast-track services $[9,10]$ to the ED. Furthermore, several strategies for improving ED throughput $[1,9]$ and output [30-34] are available.

\section{Conclusions}

The present study does not support the hypothesis that primary triage nurses divert more patients away from the ED at times of high in-hospital bed occupancy. This is reassuring, as the opposite would have implied that patients might be denied thorough medical assessment in the ED at times of hospital crowding. Interestingly, the permeability of primary triage appears to increase slightly at times of high demand for ED resources, which is contrary to its purpose.

\section{Additional files}

Additional file 1: Schematic illustration of primary triage process. (PDF $31 \mathrm{~kb}$ )

Additional file 2: Variable characteristics, multivariate models. (PDF $51 \mathrm{~kb}$ )

Additional file 3: Variable characteristics, multivariate models, stratified by shift intensity. (PDF 66 kb) 


\section{Acknowledgements}

Thanks to the staff and administrative board at the Emergency Department of Helsingborg general Hospital, for opportunities and support while immersing in on-site operations. Thanks to Emergency Department nurses and physicians, for dedication and composure.

\section{Funding}

Thanks to the Tegger foundation, the Laerdal Foundation and to Norrbottens Läns Landsting, for the project grants which made the study possible.

\section{Availability of data and material}

Access to data from Patientliggaren ${ }^{\oplus}$ and from the regional occupancy database was granted by Kl and FJ. The datasets generated during and/or analyzed during the current study are not publicly available due to the decision by the Regional Ethical Review Board in Lund. Please contact the corresponding author regarding any inquiries regarding the nature of the dataset

\section{Authors' contributions}

$\mathrm{MB}, \mathrm{MLO}$ and $\mathrm{KI}$ all participated in developing the study design. Kl obtained ethical approval for the study. LG collected and concatenated data. MB performed the statistical analyses. MB prepared all versions of the manuscript. FJ, MLO, KI and KE participated in drafting the manuscript. All authors read and approved the final manuscript.

\section{Authors' information}

$\mathrm{Kl}$ is a surgeon and was the head of the division responsible for the Emergency Department where the study was conducted. FJ is a surgeon and currently the chair of the Emergency Department where the study was conducted. MLO is a physician, a professor of medicine and the main supervisor of $\mathrm{KE}$, who is a physician and a PhD student at Lund University. $\mathrm{MB}$ is a physician and holds a PhD in clinical emergency medicine from Lund University. LG is a registered nurse and a controller in the informatics department of the hospital where the study was conducted.

\section{Competing interests}

$\mathrm{KI}$ was the head of the division responsible for the Emergency Department where the study was conducted. FJ is currently the chair of the Emergency Department where the study was conducted. All other authors declare that they have no competing interests in relation to the study.

\section{Consent for publication}

Since the manuscript contains no individual person's data, consent for publication was waived.

\section{Ethics approval and consent to participate}

The Regional Ethical Review Board in Lund granted ethical approval for the study (dnr 2013/11). The need for individual consent was waived, as the study material was limited to routinely collected administrative data.

\section{Author details}

'IKVL/Avd för medicin, Universitetssjukhuset, Hs 32, EA-blocket, plan 2, 221 85 Lund, Sweden. ${ }^{2}$ Helsingborgs lasarett, IK-enheten, S Vallgatan 5, 25187 Helsingborg, Sweden. ${ }^{3}$ Pre- och intrahospital akutsjukvård, Helsingborgs lasarett, S Vallgatan 5, 25187 Helsingborg, Sweden.

Received: 21 October 2014 Accepted: 13 September 2016 Published online: 22 September 2016

\section{References}

1. Boarding Task Force ACEP. Emergency department crowding: high-impact solutions, ACEP Task Force Report on Boarding. USA: American College of Emergency Physicians; 2008.

2. Morris Z, Beniuk K, Boyle A, Robinson S. Emergency department crowding: Towards an agenda for evidence-based intervention. Emerg Med J. 2012; 29(6):460-6.

3. Guttmann A, Schull MJ, Vermeulen MJ, Stukel TA. Association between waiting times and short term mortality and hospital admission after departure from emergency department: population based cohort study from Ontario, Canada. BMJ. 2011;342(7809):d2983.
4. Asplin B, Magid D, Rhodes K, Solberg L, Lurie N, Camargo C. A conceptual model of emergency department crowding. Ann Emerg Med. 2003;42(2): $173-80$.

5. Forero R, McCarthy S, Hillman K. Access block and emergency department overcrowding. Crit Care. 2011;15:216.

6. Rathlev N, Chessare J, Olshaker J, Obendorfer D, Mehta SD, Rothenhaus T, Crespo S, Magauran B, Davidson K, Shemin R, Lewis K, Becker JM, Fisher L, Guy L, Cooper A, Litvak E. Time series analysis of variables associated with daily mean emergency department length of stay. Ann Emerg Med. 2007; 49(3):265-71.

7. Blom M, Jonsson F, Landin-Olsson M, Ivarsson K. The probability of patients being admitted from the emergency department of Helsingborg general hospital is negatively correlated to in-hospital bed occupancy - an observational study. Int J Emerg Med. 2014;7:8.

8. Blom M, Jonsson F, Landin-Olsson M, Ivarsson K. Associations between inhospital bed-occupancy and unplanned 72 hour revisits to the Emergency Department - a register study. Int J Emerg Med. 2014:7:25.

9. Wiler J, Gentle C, Halfpenny J, Heins A, Mehrotra A, Fite D. Optimizing Emergency Department Front-End Operations. Ann Emerg Med. 2010;55(2):142-60.

10. Oredsson S, Jonsson H, Rognes J, Lind L, Goransson K, Ehrenberg A, Asplund K, Castrén M, Farrohknia N. A systematic review of triage-related interventions to improve patient flow in emergency departments. SJTREM. 2011;19:43.

11. Rowe B, Xiaoyan G, Villa-Roel C, Schull M, Holroyd B, Bullard M, Vandermeer B, Ospina M, Innes G. The Role of Triage Liaison Physicians on Mitigating Overcrowding in Emergency Departments: A Systematic Review. Acad Emerg Med. 2011;18(2):111-20.

12. Holroyd B, Bullard M, Latoszek K, Gordon D, Allen S, Tam S, Blitz S, Yoon P, Rowe B. Impact of a Triage Liaison Physician on Emergency Department Overcrowding and Throughput: A Randomized Controlled Trial. Acad Emerg Med. 2007;14(8):702-8.

13. Choi Y, Wong T, Lau C. Triage rapid initial assessment by doctor (TRIAD) improves waiting time and processing time of the emergency department. Emerg Med J. 2006;23(4):262-5.

14. Rowe B, Villa-Roel C, Guo X, Bullard M, Ospina M, Vandermeer B, Innes G, Schull MJ, Holroyd B. The Role of Triage Nurse Ordering on Mitigating Overcrowding in Emergency Departments: A Systematic Review. Acad Emerg Med. 2011; 18(12):1349-57.

15. Fry $\mathbf{M}$. Triage nurses order $\mathrm{x}$-rays for patients with isolated distal limb injuries: $\mathrm{A}$ 12-month ED study. J Emerg Nurs. 2011;27(1):17-22.

16. Khangura JK, Flodgren G, Perera R, Rowe BH, Shepperd S. Primary care professionals providing non-urgent care in hospital emergency departments. Cochrane Database Syst Rev. 2012;11:75.

17. Shepperd S, Lannin N, Clemson L, McCluskey A, Cameron I, Barras S. Discharge planning from hospital to home. Cochrane Database Syst Rev [Internet]. 2013;1:91. [Cited 2014 Oct 05].

18. Takeda A. Taylor SJC, Taylor RS, Khan F, Krum H, Underwood M. Clinical service organization for heart failure. Cochrane Database Syst Rev [Internet]. 2012:9:161. [Cited 2014 Oct 05].

19. Hernandez A, Greiner M, Hammill B, Peterson E, Curtis L, Yancy C, Peterson $E D$, Curtis LH. Relationship between early physician follow-up and 30-day readmission among medicare beneficiaries hospitalized for heart failure. JAMA. 2010:303(17):1716-22.

20. Kantonen J, Menezes R, Heinänen T, Mattila J, Mattila K, Kauppila T. Impact of the $A B C D E$ triage in primary care emergency department on the number of patient visits to different parts of the health care system in Espoo City. BMC Emerg Med. 2012;12(1):1-12.

21. Rosner B. Estimation of Sample Size and Power for Comparing Two Binomial Proportions. In: Taylor M, editor. Fundamentals of Biostatistics. 7th ed. Boston: Brooks/Cole; 2011. p. 381-90.

22. Peduzzi P, Kemper E, Concato J, Holford T, Feinstem A. A simulation study of the number of events per variable in logistic regression analysis. J Clin Epidemiol. 1996;49(12):1373-9.

23. Region Skåne. Triagehandbok. 5th ed. Malmoe: Giv Akt Information; 2011.

24. Farrokhnia N, Castren M, Ehrenberg A, Lind L, Oredsson S, Goransson K, et al. Emergency Department Triage Scales and Their Components: A Systematic Review of the Scientific Evidence. Scand J Trauma Resusc Emerg Med. 2011;19:42.

25. Farrokhnia N, Goransson K. Swedish emergency department triage and interventions for improved patient flows: A national update. Scand Trauma Resusc Emerg Med. 2011;19:72. 
26. Blom M, Landin-Olsson M, Lindsten M, Jonsson F, Ivarsson K. Patients presenting at the emergency department with acute abdominal pain are less likely to be admitted to inpatient wards at times of access block: a registry study. Scand J Trauma Resusc Emerg Med. 2015;23:78.

27. Tabachnick B, Fidell LS. Limitations to logistic regression analysis. In: Hartman S, editor. Using Multivariate Statistics. 5th ed. Boston: Pearson; 2006. p. 437-505.

28. Hosmer DW, Lemeshow S, et al. Ch. 4. In: Cressie NAC, editor. Applied logistic regression. 2nd ed. CA: Wiley; 2006. p. 47-142.

29. Anantharaman $V$, Seth P. Emergency Department overcrowding. In: Kayden S, Anderson PD, Freitas R, Platz E, editors. Emergency Department Leadership and Management: Best Principles and Practice. 1st ed. Cambridge: Cambridge University Press; 2015. p. 257-69.

30. Gallivan S, Utley M. Modelling admissions booking of elective in-patients into a treatment centre. IMA J Manage Math. 2005;16(3):305-15.

31. Fieldston ES, Hall M, Shah SS, Hain PD, Sills MR, Slonim AD, Myers AL, Cannon C, Pati S. Addressing inpatient crowding by smoothing occupancy at children's hospitals. J Hosp Med. 2011;8:466-73.

32. Black S, Proudlove N, Badrinath P, Evans DA, Ebrahim S, Frankel S, Davey Smith G, Mallet ML, Ham C, York N, Shaw R, Sutch S. Hospital bed utilisation in the NHS and Kaiser Permanente: bed management in the NHS can be improved easily. BMJ. 2004:328(7439):582-5.

33. Khanna S, Boyle J, Good N, Lind J. Unravelling relationships: Hospital occupancy levels, discharge timing and emergency department access block. Emerg Med Australas. 2012;24(5):510-7.

34. Zhu Z. Impact of different discharge patterns on bed occupancy rate and bed waiting time: A simulation approach. J Med Eng Technol. 2011;35(6-7): 338-43

\section{Submit your next manuscript to BioMed Central and we will help you at every step:}

- We accept pre-submission inquiries

- Our selector tool helps you to find the most relevant journal

- We provide round the clock customer support

- Convenient online submission

- Thorough peer review

- Inclusion in PubMed and all major indexing services

- Maximum visibility for your research

Submit your manuscript at www.biomedcentral.com/submit 